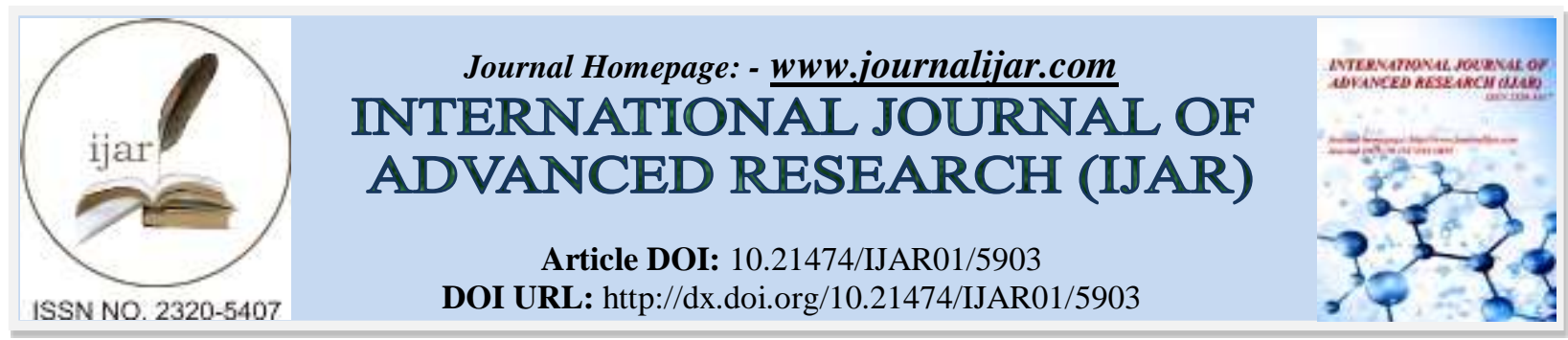

RESEARCH ARTICLE

\title{
MEASUREMENT OF ZINC CONCENTRATION IN SERUM AND FOLLICULAR FLUID TO ASSESS ITS RELATION WITH OOCYTE AND EMBRYO QUALITY IN WOMEN UNDERGOING INTRA CYTOLASMIC SPERM INJECTION.
}

\author{
Dr. Muayyad S. Abbood ${ }^{1}$, Shams A. Burhan ${ }^{2}$ and Nawal K. Al-Ani ${ }^{1}$. \\ 1. Lecture high institute for infertility diagnosis and assisted reproductive technologies, al-nahrain university, \\ baghdad-iraq. \\ 2. Prof. Dr collage of pharmacy, al-nahrain university, baghdad-iraq.
}

\section{Manuscript Info}

Manuscript History

Received: 18 September 2017

Final Accepted: 20 October 2017

Published: November 2017

Key words:-

Zinc, oocyte, embryo, ICSI.

\section{Abstract}

Background: Zinc is part of over 300 metalloenzymes found in all metabolic pathways. It is required for DNA, RNA and protein synthesis, cell mediated immunity, reproduction, and development of the epidermis and CNS.

Objectives: General population has relatively higher exposure to environmental pollution, the goal in this study is to assess the effect of Zinc concentration level in serum and follicular fluid on oocyte, embryo quality and pregnancy success in women undergoing ICSI.

Patient, Materials and Methods: This study included 70 infertile couples joined in assisted reproductive technology (ART) programs to enter ICSI cycle in high Institute for Infertility Diagnosis and Assisted Reproductive Technologies and Kamal AL-Samarai Hospital, center of fertility and IVF(Baghdad/Iraq) during the period from October 2016 to February 2017. The level of Zinc concentration will be measured and assess their effect on oocyte and embryo quality.

Results: No significant difference was observed in follicular fluid zinc (p- value $0.0859, \mathrm{P}<0.05$ ) also there was No-significant difference was observed in serum zinc $(\mathrm{P}<0.05)$ between pregnant and non- pregnant group. Serum zinc in pregnant group there was negatively correlated with (M2) type of oocyte, fertilization rate and number of embryo transfer but in no-pregnant group there was positive correlated with (M2) type of oocyte, fertilization rate and number of embryo transfer. Follicular fluid zinc in pregnant group shows negative correlated with M1, M2, rapture and abnormal type of oocyte, fertilization rate and number of embryo transfer and positive correlated with GV type. Follicular fluid zinc in pregnant group has negative correlated with fertilization rate and M2, GV type of oocyte and has positive correlated with number of embryo transfer and rapture, abnormal and M1 type of oocyte.

Conclusions: There was no Significant difference in follicular fluid and serum zinc between pregnant and no-pregnant. The 
Increasing number of oocyte lead to increase the fertilization rate, high number of embryo transfer(grade1) this lead to increase chance of pregnancy outcome.

Copy Right, IJAR, 2017,. All rights reserved.

\section{Introduction:-}

Zinc $(\mathrm{Zn})$ is a naturally occurring element. It found in the earth's crust in most rock-forming minerals. It is a lustrous, blue-white metal that burns in air with a bluish-green flame. $\mathrm{Zn}$ is the second to iron as the most an abundant trace element in the body ${ }^{(1)}$. It occurs in all living cells as a constituent of metalloenzymes involved in major metabolic pathway ${ }^{(2)}$. Zn can interact with almost all hormones and plays a significant role in homeostasis of hormones such as thyroid and steroid hormones, insulin, and pituitary hormones like prolactin ${ }^{(3)}$. Good dietary sources of $\mathrm{Zn}$ are meat, poultry, eggs, and sea food. Oysters are the richest sources of $\mathrm{Zn}$, cereals and legumes also contain significant amounts of it, but because of the presence of phytic acid in these foods, it is less available than that supplied by foods of animal origin by reducing its absorption. Absorption of $\mathrm{Zn}$ is negatively correlated to phytic acid content ${ }^{(4)}$. Zinc plays a role in ovulation and the menstrual cycle, which means that zinc deficiencies can make it harder to get pregnant. Low zinc levels have been linked to hormonal imbalances, which can cause ovarian function problems, irregularities in menstruation or even anovulation (in which women don't ovulate). Even during preconception, zinc depletion has been shown to severely disrupt egg maturation. Down the road, this deficiency can impact fertilization and egg pre-implantation development. Indeed, zinc's role is critical in the initial stages of cell division - after the egg is fertilized by sperm - and for placental development. Low plasma zinc concentrations reduce placental zinc transport and may affect the supply of zinc to the fetus, putting at risk the fetus's natural growth trajectory ${ }^{(5)}$.

\section{Patient,Material And Methods:-}

This study included 70 infertile couples enrolled in assisted reproductive technology (ART) programs to enter ICSI cycle in high Institute for Infertility Diagnosis and Assisted Reproductive Technologies and Kamal ALSamarai Hospital, center of fertility and IVF (Baghdad/Iraq) during the period from October 2016 to February 2017. The average age of included women ranged between 18 and 42 years had primary and secondary infertility with duration between2-8year.

\section{Collection of Serum and Follicular Fluid Sample :-}

A-1 milliliters of blood sample were collected by venipuncture, from each infertile woman on day of oocyte retrieval, left in plan tube and was allowed to clot for 30 minutes and centrifuged to separate the serum for 15 minutes at $3000 \mathrm{rpm}$. Sera obtained from centrifugation are stored at $-20{ }^{\circ} \mathrm{C}$ in deep freezer before the analysis and use to evaluate serum zinc,

B- 1 milliliters of follicular fluid was obtained from the first retrieved follicle to avoid contamination of blood and flush medium, and collected in plane tube. Care was taken to avoid blood contaminated samples, FF samples were centrifuged for 15 minutes at $3000 \mathrm{rpm}$ and stored at $-20{ }^{\circ} \mathrm{C}$ in deep freezer before the analysis and use to evaluate FF zinc.

\section{Measurement of Serum Zinc:-}

1 -put $1 \mathrm{ml}$ of serum sample in plane tube and complete to $10 \mathrm{ml}$ from deionized water.

2-put in mixer for 1minute.

B- The result directly read by using flame AAS at wave length $213.9 \mathrm{~nm}$ for zinc

\section{Measurement of follicular fluid Zinc :-}

1-put $1 \mathrm{ml}$ of FF sample in plane tube and complete to $10 \mathrm{ml}$ from deionized water.

2-put in mixer for one minute.

B- The result directly read by using flame AAS at wave length $213.9 \mathrm{~nm}$ for zinc.

Statistical Analysis:-

The Statistical Analysis System- SAS (2012) program was used to effect of difference factors in study parameters. Least significant difference -LSD test (ANOVA) or T-test was used to significant compare between means. Chi-square test was used to significant compare between percentage. Estimate of correlation coefficient between parameters in this study. A P value $<0.05$ was considered to be statistically significant ${ }^{(6)}$. 


\section{Results:-}

Table (1) show Compare between pregnant and non-pregnant in $\mathrm{Zn}$ in, The $\mathrm{Zn}$ level in serum expressed as (microgram/dl) of the total patients, pregnant, and non-pregnant group(67.56 \pm 1.44 and $68.42 \pm 1.64$, respectively). In this study no significant difference was observed in $\mathrm{Zn}, \mathrm{Cu}$ and $\mathrm{Mg}$ in serum between the pregnant and non-pregnant group. Zn level in FF is expressed as (microgram/L) of the total patients, pregnant, and non-pregnant group $(84.58 \pm 1.49$ and $80.83 \pm 1.50$, respectively). No significant difference was observed in $\mathrm{Zn}, \mathrm{Cu}$ and $\mathrm{Mg}$ in FF between the pregnant and non-pregnant group.

Table 1:- Compare between pregnant and non-pregnant in Zinc in serum and follicular fluid:

\begin{tabular}{|l|l|l|}
\hline The group & Mean $\pm \mathrm{SE}$ of Zn in serum (microgram/dl) & $\begin{array}{l}\text { Mean } \pm \text { SE of Zn in FF } \\
(\text { microgram/L) }\end{array}$ \\
\hline Pregnant & $67.56 \pm 1.44$ & $84.58 \pm 1.49$ \\
\hline Non-pregnant & $68.42 \pm 1.64$ & $80.83 \pm 1.50$ \\
\hline T-Test & $4.368 \mathrm{NS}$ & $4.295 \mathrm{NS}$ \\
\hline P-value & 0.697 & 0.0859 \\
\hline Mean(M) \pm Standard Error(S.E.)
\end{tabular}

In this study, in pregnant group it was found that is No significant positive correlation was observed between the $\mathrm{Zn}$ in serum and $\mathrm{M} 1(\mathrm{r}=0.08, \mathrm{P}<0.05), \mathrm{GV}(\mathrm{r}=0.15, \mathrm{P}<0.05)$ and No. of embryo transfer $(\mathrm{r}=0.12, \mathrm{P}<0.05), \mathrm{A}$ significant negative correlation was observed between the $\mathrm{Zn}$ in serum and Fertilization rate $(\%)(\mathrm{r}=0.32, \mathrm{P}<$ $0.05)$, No significant negative correlation was observed between the $\mathrm{Zn}$ in serum and $\mathrm{M} 2(\mathrm{r}=0.18, \mathrm{P}<0.05)$, and rapture $(\mathrm{r}=0.14, \mathrm{P}<0.05)$. A significant positive correlation was observed between the $\mathrm{Zn}$ in serum and abnormal $(\mathrm{r}=0.33, \mathrm{P}<0.05)$, In no pregnant group No significant positive correlation was observed between the $\mathrm{Zn}$ in serum and M1 $(\mathrm{r}=0.11, \mathrm{P}<0.05), \mathrm{GV}(\mathrm{r}=0.006, \mathrm{P}<0.05)$, No. of embryo transfer $(\mathrm{r}=0.08, \mathrm{P}<0.05)$ and raptuer $(\mathrm{r}$ $=0.02, \mathrm{P}<0.05)$, No significant negative correlation was observed between the $\mathrm{Zn}$ in serum and Fertilization rate $(\%)(\mathrm{r}=0.06, \mathrm{P}<0.05)$, Abnormal $(\mathrm{r}=0.12, \mathrm{P}<0.05)$ and $\mathrm{M} 2(\mathrm{r}=0.07, \mathrm{P}<0.05)$. In this study, in pregnant group it was found that is No significant negative correlation was observed between the $\mathrm{Zn}$ in FF and M1 $(\mathrm{r}=0.05, \mathrm{P}<0.05)$ , abnormal $(\mathrm{r}=0.11, \mathrm{P}<0.05)$, No. of embryo transfer $(\mathrm{r}=0.13, \mathrm{P}<0.05)$ and rapture $(\mathrm{r}=0.11, \mathrm{P}<0.05)$, A significant negative correlation was observed between the $\mathrm{Zn}$ in FF and $\mathrm{M} 2(\mathrm{r}=0.32, \mathrm{P}<0.05)$, and Fertilization rate $(\%)(\mathrm{r}=$ 0.32,P < 0.05). No significant positive correlation was observed between the $\mathrm{Zn}$ in FF and $\mathrm{GV}(\mathrm{r}=0.13, \mathrm{P}<0.05)$. In no pregnant group no significant positive correlation was observed between the $\mathrm{Zn}$ in FF and M1(r=0.08,P $<0.05)$ abnormal $(\mathrm{r}=0.05, \mathrm{P}<0.05)$, rapture $(\mathrm{r}=0.02, \mathrm{P}<0.05)$ and No. of embryo transfer $(\mathrm{r}=0.13, \mathrm{P}<0.05)$. No significant negative correlation was observed between the $\mathrm{Zn}$ in FF and M2(r = 0.08,P $<0.05), \mathrm{GV}(\mathrm{r}=0.06, \mathrm{P}<$ $0.05)$ and Fertilization rate $(\%)(\mathrm{r}=0.12, \mathrm{P}<0.05)$. As show in(table 2$)$.

Table 2:- Correlation between $\mathrm{Zn}$ in Follicular Fluid and serum with Type of oocyte Fertilization rate and number of embryo transfer in pregnant and non-pregnant.

\begin{tabular}{|c|c|c|c|c|}
\hline Type of oocyte & $\begin{array}{l}\mathrm{Zn} \quad(\text { microgram} / \mathrm{L}) \text { in } \\
\text { pregnant in } \mathrm{FF}\end{array}$ & $\begin{array}{l}\mathrm{Zn}(\text { microgram/L)in } \\
\text { non- pregnant in FF }\end{array}$ & $\begin{array}{l}\mathrm{Zn}(\text { microgram/dl)in } \\
\text { serum of pregnant }\end{array}$ & $\begin{array}{l}\mathrm{Zn} \\
\text { (microgram/dl)in } \\
\text { serum of non- } \\
\text { pregnant }\end{array}$ \\
\hline M1 & $-0.05 \mathrm{NS}$ & $0.08 \mathrm{NS}$ & $0.08 \mathrm{NS}$ & $0.11 \mathrm{NS}$ \\
\hline M2 & $-0.32 *$ & $-0.08 \mathrm{NS}$ & $-0.18 \mathrm{NS}$ & $-0.07 \mathrm{NS}$ \\
\hline $\mathrm{Gv}$ & $0.13 \mathrm{NS}$ & $-0.06 \mathrm{NS}$ & $0.15 \mathrm{NS}$ & $0.006 \mathrm{NS}$ \\
\hline Abnormal & $-0.11 \mathrm{NS}$ & $0.05 \mathrm{NS}$ & $0.33 *$ & $-0.12 \mathrm{NS}$ \\
\hline Rapture & $-0.11 \mathrm{NS}$ & $0.02 \mathrm{NS}$ & $-0.14 \mathrm{NS}$ & $0.02 \mathrm{NS}$ \\
\hline $\begin{array}{l}\text { Fertilization rate } \\
(\%)\end{array}$ & $-0.32 *$ & $-0.12 \mathrm{NS}$ & $-0.32 *$ & $-0.06 \mathrm{NS}$ \\
\hline $\begin{array}{l}\text { No. of embryo } \\
\text { transfer }\end{array}$ & $-0.13 \mathrm{NS}$ & $0.13 \mathrm{NS}$ & $0.12 \mathrm{NS}$ & $0.08 \mathrm{NS}$ \\
\hline
\end{tabular}




\section{Discussion:-}

Environmental factors differ between areas with higher amounts of pollutants closer to sources of industrialization. Environmental factors, such as exposure to heavy metals, can cause reproductive dysfunction in women ${ }^{(7)}$. Zinc $(\mathrm{Zn})$ is the unique trace intracellular element required for a number of cellular processes including cell proliferation, reproduction, immune function, and defense against free radicals ${ }^{(8),(9)}$. In the present study, the results showed that being serum $\mathrm{Zn}$ concentration with pregnant group was (67,56) microgram/dl among those with average serum $\mathrm{Zn}$ concentration in non-pregnant group $(68,42) \mathrm{microgram} / \mathrm{dl}$. It is less than the normal Value (80-150) microgram/dl so it's not highly effect on pregnant rate ${ }^{(10)}$. The results presented in this study confirm the findings of published reports in an article by Yan Sun et al (11). Who have found no significant differences was detected in the follicular fluid concentrations of $\mathrm{Zn}$ on the day of oocyte retrieved $(\mathrm{P}>0.05)$. In the present study $\mathrm{Zn}$ in pregnant group was statistically negative correlation with $\mathrm{M} 2$, rapture type of oocyte and Fertilization rate (\%), positive correlation with M1, GV and abnormal type of oocyte and No. of embryo transfer, Studies have demonstrated that concentration of Zn Nutrition affects not only the number of oocytes that ovulate but also their quality, Fertilization rate (\%) and No. of embryo transfer. While the only definitive measure of oocyte quality is its ability to form a blastocyst, and indeed viable young, numerous proxy measures of oocyte quality are used, including the attainment of metaphase II following in vitro maturation $^{(12)}$. on the other hand, $\mathrm{Zn}$ in non-pregnant group was statistically positive correlation with M1, GV, rapture type of oocyte and No. of embryo transfer, Negative correlation with M2, abnormal type of oocyte and Fertilization rate (\%) This agreement with Studies have demonstrated Low zinc levels have been linked to hormonal imbalances, which can cause ovarian function problems, irregularities in menstruation or even anovulation (in which women don't ovulate). Even during preconception, zinc depletion has been shown to severely disrupt egg maturation. Down the road, this deficiency can impact fertilization and egg pre-implantation development ${ }^{(13)}$. In the present study, the results showed that no significant difference between Follicular fluid $\mathrm{Zn}$ concentration between pregnant and non-pregnant group. $\mathrm{Zn}$ in pregnant group was statistically negative correlation with M1, rapture, abnormal type of oocyte, positive correlation with GV and M2 type of oocyte, Fertilization rate (\%), and No. of embryo transfer the results presented in this study confirm the findings of published reports in an article ${ }^{(14)}$. Have found high concentrations of $\mathrm{Zn}$ can inhibit production of cAMP and P4 induced by FSH in chicken granulosa cell of dominant follicle, slowing down maturity of oocyte. on the other hand, $\mathrm{Zn}$ in non-pregnant group was statistically positive correlation with M1, abnormal, rapture type of oocyte, and No. of embryo transfer and No. of embryo transfer, negative correlation with GV and M2 type of oocyte and Fertilization rate $(\%)$. This agreement with result of study ${ }^{(15)}$ that found maintaining $\mathrm{Zn}$ at an optimal level is critical to oocyte development and ovulation. beside statistically negative correlations observed between follicular fluid concentrations of $\mathrm{Zn}$ and the fertilization rate, $\mathrm{M} 2$ and abnormal type of oocyte a positive correlation trend was found between follicular fluid concentrations of $\mathrm{Zn}$ and the No. of MI oocytes and cleavage rate in IVF patients Collectively, these data imply that $\mathrm{Zn}$ may play important roles in fertilization and early embryonic growth.

\section{References:-}

1- Henkel, R., Defosse, K., and Koyro, H. W. Estmate of oxygen consumption and intercellular zinc concentration of human spermatozoa in relation to motility: Asian, J. Anodrol.2003;5:3-8.

2- Zhang D, Gao J, Zhang K, Liu X, Li J. Effects of chronic cadmium poisoning on $\mathrm{Zn}, \mathrm{Cu}, \mathrm{Fe}, \mathrm{Ca}$, and metallothionein in liver and kidney of rats. Biological trace element research. 2012;149(1):57-63.

3- Brandao-Neto, J., Madureira, G., Mendonca, B.B., Bloise, W. and Castro, A.V. Endocrine interaction between zinc and prolactin. An interpretive review. Biol. Trace Elem. Res.1995; 49:139-149.

4- Haslett, C., Chilvers, R.E., Hunter, A.A.J. and Boon, A.N. Nutritional factors in disease. In: Davidsons: Principles and Practice of Medicine. $18^{\text {th }}$ (eds). Churchill Livingstone. London.1999. pp. 514-518.

5- Endre, L., Beck, F. and Prasad, A. The role of zinc in human health.J. Trace. Elem. Exp. Med.1990; $3: 337$ - 75.

6- SAS. 2012. Statistical Analysis System, User's Guide. Statistical. Version 9.1 ${ }^{\text {th }}$ ed. SAS. Inst. Inc. Cary. N.C. USA.

7- Mendola P, Messer LC, Rappazzo K. Science linking environmental contaminant exposures with fertility and reproductive health impacts in the adult female. Fertil Steril. 2008;89: e81-94.

8- Włostowski T. On metallothionein, cadmium, copper and zinc relationships in the liver and kidney of adult rats. Comparative Biochemistry and Physiology Part C: Comparative Pharmacology. 1992; 103:35-41. 
9- Ferguson E. M., Ashworth C. J., Edwards S. A., Hawkins N., Hepburn N., Hunter M. G. Effect of different nutritional regimens before ovulation on plasma concentrations of metabolic and reproductive hormones and oocyte maturation in gilts. Reproduction.2003;126:61-71.

10- Písa J1, Cibulka J, Ptácek M. Effect of subcutaneous application of a single cadmium dose on oocyte maturation in vitro, Physiol Bohemoslov. 1990; 39:185-90.

11- Yan Sun., Yuan Lin2., Min Niu3., Yuefan Kang1., Shengrong Du1., Beihong Zheng., Follicular fluid concentrations of zinc and copper are positively associated with in vitro fertilization outcomes. Int J Clin Exp Med. 2017; 10:3547-3553.

12- Ferguson E. M., Ashworth C. J., Edwards S. A., Hawkins N., Hepburn N., Hunter M. G. Effect of different nutritional regimens before ovulation on plasma concentrations of metabolic and reproductive hormones and oocyte maturation in gilts. Reproduction.2003;126:61-71.

13- Endre, L., Beck, F. and Prasad, A. The role of zinc in human health.J. Trace. Elem. Exp. Med.1990; 3: 337 75.

14- Goodman HM. Basic Medical Endocrinology.4PthP ed. Elsevier-Academic Press. 2009. pp. 257-75.

15- Tolunay HE, Sukur YE, Ozkavukcu S, Seval MM, Ates C, Turksoy VA, Ecemis T, Atabekoglu CS, Ozmen B, Berker B, Sonmezer M. Heavy metal and trace element concentrations in blood and follicular fluid affect ART outcome. Eur J Obstet Gynecol Reprod Biol. 2016; 198: 73-77. 